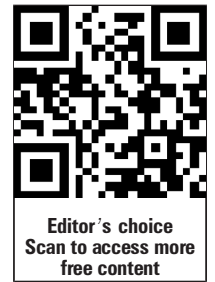

Center for Gun Policy and Research, Johns Hopkins Bloomberg School of Public Health, Baltimore, Maryland, USA

\section{Correspondence to}

Dr Katherine A Vittes, Center for Gun Policy and Research, Johns Hopkins Bloomberg School of Public Health, 624 North Broadway, Baltimore, MD 21205, USA; kvittes@jhsph.edu

Accepted 7 March 2012 Published Online First 23 June 2012

\title{
Legal status and source of offenders' firearms in states with the least stringent criteria for gun ownership
}

\author{
Katherine A Vittes, Jon S Vernick, Daniel W Webster
}

\begin{abstract}
Background Gun possession by high-risk individuals presents a serious threat to public safety. U.S. federal law establishes minimum criteria for legal purchase and possession of firearms; many states have laws disqualifying additional categories for illegal possession. Methods We used data from a national survey of state prison inmates to calculate: 1) the proportion of offenders, incarcerated for crimes committed with firearms in 13 states with the least restrictive firearm purchase and possession laws, who would have been prohibited if their states had stricter gun laws; and 2) the source of gun acquisition for offenders who were and were not legally permitted to purchase and possess firearms.

Results Nearly three of ten gun offenders (73 of 253 or $28.9 \%$ ) were legal gun possessors but would have been prohibited from purchasing or possessing firearms when committing their most recent offense if their states had stricter prohibitions. Offenders who were already prohibited under current law acquired their gun from a licensed dealer, where a background check is required, five times less often than offenders who were not prohibited $(3.9 \%$ vs. $19.9 \%$; $\left.\chi^{2}=13.31 ; p \leq 0.001\right)$. Nearly all $(96.1 \%)$ offenders who were legally prohibited, acquired their gun from a supplier not required to conduct a background check.

Conclusions Stricter gun ownership laws would have made firearm possession illegal for many state prison inmates who used a gun to commit a crime. Requiring all gun sales to be subject to a background check would make it more difficult for these offenders to obtain guns.
\end{abstract}

\section{INTRODUCTION}

Gun violence has long been one of the most significant public safety and social problems in the USA. In the USA, in 2008, gun violence resulted in 12179 homicides and an estimated 56626 assaultive injuries serious enough to warrant a hospital emergency room visit. ${ }^{1}$ Among high-income countries, the USA is unique in its extraordinarily high rate of homicides. This disparity is most striking for homicides committed with firearms where the US rate is 20 times higher than other high-income countries. ${ }^{2}$

Despite the magnitude of the problem, US gun policy rarely considers appropriate criteria for disqualifying someone from lawfully possessing a firearm. Federal law disqualifies certain groups of high-risk individuals from owning guns, including felons, fugitives, unlawful users of or those addicted to controlled substances, those who have been 'adjudicated as a mental defective' or committed to a mental institution, individuals who have been dishonourably discharged from the armed forces, persons subject to certain domestic violence restraining orders, persons less than the age of 18 years (for handguns) and domestic violence misdemeanants. Federal law does not set a minimum age requirement for the legal possession of long guns (ie, rifles and shotguns).

Although the federal firearm prohibitions apply minimum standards for all US states, many states have enacted broader disqualifications for firearm possession including: a minimum age of 21 for all guns; convictions for some misdemeanour crimes involving violence, firearms or drugs; multiple convictions for alcohol-related offences; or convictions for serious crimes committed as a juvenile. ${ }^{4}$

Research supports the underlying premise of laws that widen exclusionary criteria for firearm possession: that some groups have higher rates of criminal offending than do those without a criminal history or other indicia of risk. ${ }^{5-9}$ For example, Wintemute and colleagues found that individuals denied legal handgun purchase, as a result of a new California law expanding firearm prohibitions to include misdemeanants convicted of crimes of violence, were less likely to commit a new crime of violence than were demographically-matched Californian misdemeanants who had been approved for handgun sales during the years just prior to the new restrictions. ${ }^{9}$ A study of homicide offenders in Illinois found that $42 \%$ would have been prohibited from possessing firearms as a result of a prior felony conviction; however, convictions for misdemeanours as an adult or more serious crimes as a juvenile were not reported. ${ }^{6}$

Under federal law, persons buying guns from licensed gun dealers must undergo a criminal history background check. ${ }^{10}$ But federal law and the law of most states do not require firearm sellers who are not licensed gun dealers to verify that purchasers of firearms are legally qualified to possess a firearm such as through a background check. ${ }^{4}$ Understanding how those with and without a criminal history acquire guns can also inform policies intended to keep guns from prohibited persons.

Prior research on firearm acquisition suggests that incarcerated adults often obtain their guns from casual sources such as from friends and family members, and 'off the street.'11-13 To our knowledge, whether and to what extent the source varies based on the legal status of the purchaser has not been investigated.

Therefore, the goals of the current study are to: (1) identify the proportion of state prison inmates 
incarcerated for gun-related offences in states with the least strict standards for firearm purchase and possession who would have been prohibited from possessing firearms if laws in their states had included additional exclusion criteria and (2) describe how these inmates acquired their firearms.

\section{METHODS}

\section{Data}

This study used data from the most recent (2004) Survey of Inmates in State Correctional Facilities (SISCF), a nationallyrepresentative survey of state prison inmates administered by the Bureau of the Census for the US Department of Justice. ${ }^{14}$ The 2004 SISCF consisted of computer-assisted personal interviews conducted between October 2003 and May 2004. Inmates were asked about a broad range of topics including: demographic characteristics; offences for which they were currently serving time; prior criminal history; gun possession and use; prior drug and alcohol use and treatment; and physical and mental health status. In the 2004 survey, 14499 inmates were interviewed. Of those eligible to participate in the study, $89.1 \%$ participated.

Additional information about data collection and analysis methodology for the SISCF is available from the University of Michigan's Inter-university Consortium for Political and Social Research. ${ }^{15}$ Prior research using data from the SISCF include studies on incarcerated women, veterans and parents. ${ }^{16-18}$ No reported studies have used SISCF data on inmates who used firearms in their most recent crimes.

\section{Study sample}

To focus on the potential effects of broadening state laws regarding firearm restrictions, we limited our analysis to offenders currently serving time for an offence committed with a firearm in states that, as of 2004, did not have laws prohibiting persons in the following five groups from purchasing or possessing a firearm: (1) persons less than 21 years of age; (2) persons convicted of a serious juvenile offence; (3) violent misdemeanants; (4) drug misusers; and (5) alcohol abusers. To identify states meeting these criteria, we consulted the Bureau of Justice Statistics 2004 Survey of State Procedures Related to Firearm Sales, ${ }^{19}$ supplemented by legal research to confirm some state laws

Because domestic violence misdemeanants are already prohibited from purchasing or possessing firearms under federal law, ${ }^{20-22}$ we included states with laws that prohibited domestic violence misdemeanants if the states did not also prohibit other violent misdemeanants from purchasing or possessing firearms. In addition, although federal law restricts firearm purchase or possession for drug misusers, the law's definition of a drug misuser does not provide objective criteria that can be implemented via a background check, limiting its practical use. ${ }^{23} \mathrm{We}$ excluded states with separate legal restrictions on possession of firearms by those convicted of serious offences, not technically classified as felonies, when committed by a juvenile.

Nine states-Arkansas, Idaho, Louisiana, Michigan, Mississippi, Montana, New Hampshire, Vermont and Wyoming-lacked all five types of expanded firearm disqualifications. Four additional states-Georgia, Maine, New Mexico and Wisconsin-lacked these expanded disqualifications with some exceptions. For example, New Mexico had a minimum age law stating that handgun possession is unlawful by persons $<19$-years-old ${ }^{24}$ and Wisconsin restricted individuals convicted of a felony as a juvenile only if the offence occurred on or after 21 April $1994 .{ }^{25}$ We excluded a total of 12 cases meeting these exceptions, because they were already prohibited from firearm purchase and possession under state law. The final sample consisted of 13 states, though there were no inmates meeting our case definition in two states (New Hampshire, Wyoming; see table 1).

\section{Measures}

To determine whether offenders had a firearm while committing the crime for which they were currently incarcerated, SISCF interviewers asked, 'Did you use, carry or possess a weapon when the (...offense...) occurred?' If the answer was 'yes,' the interviewer asked, 'What kind of weapon was it?' Offenders who said they used a firearm were included in our analyses. Offenders who reported using a firearm in their current crime were asked follow-up questions, including questions about the type of gun(s) (eg, handgun, shotgun, rifle), how and where they obtained the gun, whether they fired it, and their reasons for having it.

SISCF interviewers also asked the offenders a series of questions about their prior arrests and convictions leading to probation or incarceration. Those who had been convicted and sentenced to probation or incarceration were asked about the type of offence, length of sentence, and whether they were sentenced as a juvenile or as an adult for up to 10 prior probations and 10 prior incarcerations. Offence information for juvenile convictions leading to probation and no incarceration was not collected in the SISCF.

To examine the potential for current and expanded disqualifications to curtail gun crime, we categorised offenders into the following groups based on their prior criminal convictions: (1) those who would have no firearm disqualification even under stricter state laws (described below); (2) those who were disqualified under current federal law; and (3) those who were legal firearm possessors under current federal law, but who would have been prohibited in states with stricter standards.

We further categorised offenders in the third group-those who might be impacted if the laws in their states were changed-based on whether they fell into any of the following categories: (1) age 18-20 years at incarceration for their current offence if that offence involved a handgun; (2) less than age 21 years at incarceration for their current offence if that offence involved a long gun; (3) committed a prior serious crime as a juvenile (<18-years-old); (4) conviction for a violent or firearms-related misdemeanour; (5) convictions for two or more drugrelated misdemeanours; and (6) convictions for two or more alcohol-related misdemeanours. These laws were chosen because each is in effect in at least some states. ${ }^{19}$ Violent and firearmrelated misdemeanours included convictions for a simple assault or a weapons offence. Drug-related misdemeanours included convictions for driving under the influence of drugs, possession or use of marijuana and unspecified drug-related offences (but did not include drug-related offences involving heroin, powder cocaine or crack cocaine which are generally felonies). Alcoholrelated misdemeanours included DUI/DWI convictions or convictions for public drunkenness.

\section{Analysis}

We first calculated the proportion of offenders who would have been legally prohibited from purchasing or possessing firearms if their states had a variety of stricter laws. We then examined the method and source of firearm acquisition for offenders and calculated $\chi^{2}$ statistics to identify any significant differences between offenders who were currently prohibited versus offenders who were not prohibited from purchasing and possessing firearms. 
Table 1 Demographic and offence characteristics of state prison inmates incarcerated for an offence committed with a firearm in 13 states $(n=253)$

\begin{tabular}{|c|c|}
\hline & n (\%) \\
\hline \multicolumn{2}{|l|}{ Demographic characteristics } \\
\hline \multicolumn{2}{|l|}{ Sex } \\
\hline Male & $234(92.5)$ \\
\hline Female & $19(7.5)$ \\
\hline \multicolumn{2}{|l|}{ Age when sentenced for current offence (years) } \\
\hline $14-17$ & $48(19.0)$ \\
\hline $18-20$ & $58(22.9)$ \\
\hline $21-24$ & $46(18.2)$ \\
\hline $25-29$ & $35(13.8)$ \\
\hline 30 and older & $66(26.1)$ \\
\hline \multicolumn{2}{|l|}{ Race/ethnicity } \\
\hline Non-Hispanic Black & $169(66.8)$ \\
\hline Non-Hispanic White & $63(24.9)$ \\
\hline Hispanic & $9(3.6)$ \\
\hline Other & $12(4.7)$ \\
\hline \multicolumn{2}{|l|}{ Education $(n=251)$} \\
\hline Less than high school & $185(73.7)$ \\
\hline High School or equivalent & $41(16.3)$ \\
\hline More than high School & $25(10.0)$ \\
\hline \multicolumn{2}{|l|}{ Marital status $(n=252)$} \\
\hline Never married & $177(70.2)$ \\
\hline Divorced/separated/widowed & $48(19.1)$ \\
\hline Married & $27(10.7)$ \\
\hline \multicolumn{2}{|l|}{ Employed in the month before incarceration $(n=246)$} \\
\hline Full-time & $129(52.4)$ \\
\hline Part-time/occasional & $24(9.8)$ \\
\hline Unemployed: looking for work & $32(13.0)$ \\
\hline Unemployed: not looking for work & $61(24.8)$ \\
\hline \multicolumn{2}{|l|}{ State of current offense } \\
\hline Arkansas & $21(8.3)$ \\
\hline Georgia & $64(25.3)$ \\
\hline Idaho & $5(2.0)$ \\
\hline Louisiana & $39(15.4)$ \\
\hline Maine & $1(0.4)$ \\
\hline Michigan & $67(26.5)$ \\
\hline Mississippi & $27(10.7)$ \\
\hline Montana & $5(2.0)$ \\
\hline New Hampshire & $0(0)$ \\
\hline New Mexico & $13(5.1)$ \\
\hline Vermont & $1(0.4)$ \\
\hline Wisconsin & $10(4.0)$ \\
\hline Wyoming & $0(0)$ \\
\hline \multicolumn{2}{|l|}{ Current offences* $\dagger$} \\
\hline \multicolumn{2}{|l|}{ Violent offences } \\
\hline Murder/voluntary non-vehicular manslaughter & $86(34.0)$ \\
\hline Robbery & $75(29.6)$ \\
\hline Aggravated assault/assault on police officer & $32(12.6)$ \\
\hline Other violent acts & $6(2.4)$ \\
\hline \multicolumn{2}{|l|}{ Property offences } \\
\hline Burglary & $6(2.4)$ \\
\hline Other property offences & $3(1.2)$ \\
\hline \multicolumn{2}{|l|}{ Drug offences } \\
\hline Trafficking & $15(5.9)$ \\
\hline Possession or use & $7(2.8)$ \\
\hline \multicolumn{2}{|l|}{ Public order offences } \\
\hline Weapons offences & $19(7.5)$ \\
\hline Parole/probation violation or contempt & $2(0.8)$ \\
\hline Other public order offences & $2(0.8)$ \\
\hline
\end{tabular}

Table 1 Continued

\begin{tabular}{|c|c|}
\hline & n (\%) \\
\hline \multicolumn{2}{|c|}{ Type of gun used in current offense } \\
\hline Handgun & $204(80.6)$ \\
\hline Rifle & $30(11.9)$ \\
\hline Shotgun & $25(9.9)$ \\
\hline Other firearm & $4(1.6)$ \\
\hline
\end{tabular}

\section{RESULTS}

The overall SISCF sample of 50 states included 14499 inmates, 2046 of whom used a gun in the crime for which they were incarcerated. The distribution of the total sample of gun users was similar to the 13 states in our sample with regard to crime type, type of gun, sex, education, marital status and employment status. Our 13-state sample had a somewhat higher proportion of younger (age 14-17 years) and non-Hispanic Black offenders than for all 50 states.

\section{Sample characteristics}

Our initial sample consisted of 281 offenders who were incarcerated for offences involving firearms from the 13 states with the most lenient firearm restrictions (no stricter than existing federal law). Due to missing or insufficiently specific information about the nature of the prior convictions, 28 offenders were excluded from the analyses for a final sample of 253. The majority of the respondents came from Georgia, Louisiana, Michigan, Mississippi and New Mexico. Some of the more populous US states (eg, California, New York, Texas) were excluded from our analysis because they did not meet our legal inclusion criteria.

Three-quarters $(n=190)$ of offenders committed their current offence (ie, the offence for which they were serving time when the interview occurred) in their state of residence. All offenders were sentenced as adults and age at sentencing for the current incarceration ranged from 14 to 55 years with a mean of 25 years. A majority of the offenders were male subjects, nonHispanic Black, had not completed high school, were employed in the month before they were incarcerated and had never been married (table 1).

\section{Current offences}

More than three-quarters $(n=199)$ of the offenders were serving time for a violent offence at the time of the SISCF interview. In all, $43 \%$ of these violent offenders were incarcerated for an attempted or completed murder, or voluntary non-vehicular manslaughter (table 1). The remainder of the sample was incarcerated for property, drug or public order offences (all involving firearms).

Although fewer than half $(44.3 \%)$ of the offenders reported that they fired a gun while committing the current crime, most (83.4\%) identified one or more other or additional reasons for possessing the gun, including using the gun to scare the victim(s) $(42.7 \%)$, or for self-protection $(32.4 \%)$.

\section{Legal status for firearm possession prior to firearm offence leading to current incarceration}

Inmates were categorised into three mutually-exclusive groups based on their actual or potential legal status for firearm possession (table 2$)$. In all, 31\% $(n=78)$ of offenders would not 
Table 2 Firearm prohibition status of state prison inmates incarcerated for offence committed with firearm in 13 states $(n=253)$

\begin{tabular}{lr} 
& $\mathbf{n}(\%)$ \\
\hline May possess even under stricter standards & 78 (30.8) \\
$\quad$ No prior arrests or convictions and offender age $\geq 21$ years & 28 (11.1) \\
Prior arrests but no convictions and offender age $\geq 21$ years & 34 (13.4) \\
Prior non-disqualifying misdemeanour convictions, and no convictions & 16 (6.3) \\
for serious juvenile offence, and offender age $\geq 21$ years & 102 (40.3) \\
Prohibited under current state or federal laws & 69 (27.3) \\
Prior adult ( $\geq 18$ years) felony conviction(s) or dishonourable discharge & 33 (13.0) \\
Offender age $<18$ years at sentencing and used handgun in current offence & 73 (28.9) \\
Would be prohibited only under stricter standards* & 43 (17.0) \\
Handgun offender age 18-20 years at sentencing for current offence & 17 (6.7) \\
Long gun offender age 1-20 years at sentencing for current offence & 13 (5.1) \\
Prior conviction for serious juvenile offence & 9 (3.6) \\
Prior conviction for firearms or violent misdemeanour & 2 (0.8) \\
Prior conviction for 2+ drug misdemeanours & 1 (0.4) \\
Prior conviction for 2+ alcohol misdemeanours &
\end{tabular}

*These subcategories are not mutually exclusive.

have been disqualified from firearm possession based on prior convictions or minimum age even if their states had laws prohibiting the legal purchase and possession of firearms by persons <21-years-old, persons with a conviction for a serious juvenile offence, violent misdemeanants, and drug and alcohol misusers.

In the second group, $40 \%(n=102)$ of offenders were already prohibited from legal firearm possession under current state or federal law and, thus, would be unaffected by the implementation of the stricter firearm prohibition standards we considered.

The third group consists of 73 offenders (28.9\%) who were not prohibited under current standards, but would have been prohibited if their states adopted stricter standards similar to those already in place in a number of other states. Most of this group $(58.9 \%$ and $17.0 \%$ of all firearm offenders, $n=43)$ would have been prohibited if their state had a law that raised the minimum age to possess a handgun to 21 years. An additional 17 offenders would have been prohibited if their state passed a law restricting possession to all firearms, including long-guns, for persons $<21$ years. If persons convicted of a serious crime as a juvenile were to become prohibited, it would have been illegal for 13 offenders $(5.1 \%$ of all firearm offenders) to purchase or possess a firearm. Nine offenders (3.6\% of all firearm offenders) would also have been disqualified if their states had prohibited persons convicted of a violent or firearms-related misdemeanour from purchasing or possessing a firearm. Two offenders would have been prohibited if states were to restrict firearm purchase and possession for those with two or more drug-related misdemeanours and one offender would be prohibited if the same restriction were applied to alcohol-related misdemeanours.

\section{How and where criminals obtained their firearms}

About eight of every 10 offenders reported using a handgun (vs rifle or shotgun) in the offence for which they were serving time. Half of the offenders reported that they had bought the gun used in the crime (table 3). The second most common method of gun acquisition-cited by fewer than one in five offenders-was borrowing or holding the gun for someone. Regardless of how they obtained the gun, friends and family members were the most common source (34.0\%), followed by drug dealers or other black market sources (30.4\%). Only $13.4 \%$ got the gun directly from a gun store or pawnshop where federal law requires prospective firearm purchasers to pass a background check. It is important to recognise, however, that table 3 represents only the most recent acquisition of a specific gun: it does not indicate whether the gun ever passed through a particular distribution channel (eg, a gun show).

There were few differences between the groups of offenders with regard to how and where they got the gun used in their most recent offence. More than half $(55.6 \%)$ of offenders for whom firearm purchase and possession was legal under current standards (adding the 45 inmates who would be legal even under stricter standards with the 39 inmates who would be prohibited only under stricter standards) bought or traded for the gun used in their most recent crime compared with two-fifths (39.2\%) of offenders who were prohibited under current state or federal law $\left(\chi^{2}=6.56 ; p \leq 0.01\right)$. Offenders who were prohibited from purchasing and possessing a gun under current law acquired their gun from a licensed dealer, where a background check would be required, five times less often than offenders who were not prohibited $\left(3.9 \%\right.$ vs $\left.19.9 \% ; \chi^{2}=13.31 ; p \leq 0.001\right)$. Similarly, nearly all $(96.1 \%)$ offenders who were legally prohibited from possessing a firearm acquired their gun from a supplier not required to conduct a background check.

\section{DISCUSSION}

Our findings indicate that $40 \%$ of offenders incarcerated for committing crimes with a gun in the 13 US states with the least strict standards for legal firearm purchase and possession were in possession of the gun illegally. If these states had adopted more restrictive standards like those in place in a number of other states, an additional $29 \%$ of the persons incarcerated for committing a crime with a firearm would have been legally prohibited from possessing a firearm at the time of their current offence. The vast majority of these individuals-nearly a quarter of the entire sample of firearm offenders-would have been prohibited if the minimum legal age for possessing any type of firearm was 21 years. An additional 9.9\% would have been legally prohibited from firearm possession as a result of convictions for serious crimes as a juvenile or for misdemeanours involving violence, firearms, drugs or alcohol.

Nearly one in five offenders was $<18$-years-old at the time they were sentenced for the current offence; $41.9 \%$ were less than age 21 when sentenced. An even greater proportion would 
Table 3 Source of gun used in current offence by state prison inmates incarcerated for offence committed with firearm in 13 states, by firearm prohibition status*

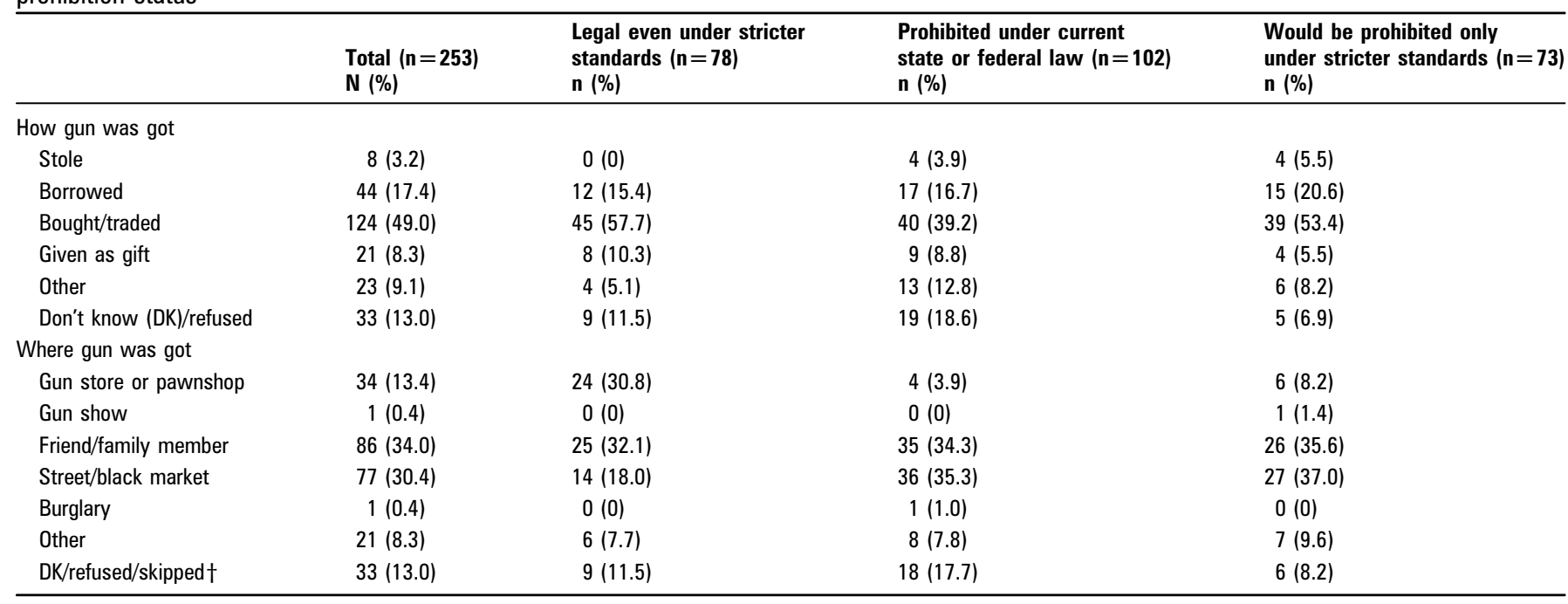

*If inmate used more than one gun in current offence, response pertains to the most recently acquired gun.

†Respondents who refused to disclose how they got the gun were not subsequently asked where they got it.

have fallen into the $<18$ group if we had data on offenders' age at the time the offence occurred rather than age at incarceration. These findings underscore the importance of minimum-age restrictions for firearms possession and disqualifications for serious offences committed as juveniles, even if the duration of these disqualifications is limited.

It is also important to consider the political feasibility of any new restrictions on access to firearms. In a 1998 survey, a large majority of respondents-including the majority of gun owners-favoured laws that would restrict guns from various categories of misdemeanants including assault and battery without a lethal weapon or serious injury, driving under the influence of alcohol, and carrying a concealed weapon without a permit. ${ }^{26}$ Although public support was strong for a variety of firearm laws, firearm restrictions based on criminal history may be among the most politically feasible. ${ }^{2327}$ Each firearm policy considered in this study is currently law in at least some states.

Although setting appropriate standards for legal firearm ownership is important, it is equally important to make sure that databases used to screen gun purchasers and ascertain legal status for gun possession are up-to-date so that prohibited individuals can be identified. For example, juvenile convictions must be recorded in an accessible database so that they are picked up in background checks in order for prohibitions for serious offences committed as a juvenile to be useful in restricting the legal purchase and possession of firearms in this high-risk group.

Relatively few offenders purchased their guns directly from licensed firearms dealers. Only 3.9\% of individuals disqualified based on current federal or state prohibitions and $3.8 \%$ who were $<21$-years-old at the time of their incarceration obtained their gun from a licensed firearms dealer. Presumably most, if not all, of these prohibited individuals purchased their firearm prior to becoming a prohibited person. Among individuals who appeared to be legally qualified to purchase firearms, only one in five $(19.9 \%)$ obtained their firearm directly from a licensed firearm dealer, perhaps to avoid having their firearms transactions recorded and therefore traceable to the purchaser. Given offenders' preferences for new firearms, ${ }^{13}{ }^{28}$ it is noteworthy how criminals avoid the regulated gun market of licensed sellers and prefer the largely unregulated market involving unlicensed sellers where new guns may be harder to obtain. The lack of regulation of firearm sales by unlicensed sellers is likely to significantly limit the government's ability to keep firearms from prohibited individuals. ${ }^{28}$ Requiring all gun sales to be subject to a background check, and holding sellers accountable for failure to do so, are policies that could address this problem. ${ }^{29}$

To our knowledge, this is the first study to use data on gun offenders' age and criminal histories to examine the potential benefits of strengthening the criteria for legal firearm possession. Nonetheless, it is subject to several limitations. The data used in this analysis come from inmates' self-report. As such, they share the limitations inherent to all self-report data (eg, recall and social desirability bias). And although the data were drawn from a nationally-representative survey of state prison inmates, they are not necessarily representative of state prison populations. In addition, the 13 states in our sample may not have the same distribution of offenders as in all 50 states. For example, the five states with the most offenders in our sample may be more urban, on average, than the USA as a whole. We chose states for inclusion in the sample based on their laws in 2004, the year the SISCF survey took place. These laws may be different from the laws that were in effect at the time the offenders were convicted for their prior offences, though it is rare for laws prohibiting certain persons from owning guns, based on criminal history, to be repealed. Moreover, we were unable to determine whether the guns used in the current crimes were obtained in the state in which the crime was committed. This is particularly relevant for considering criteria for firearm purchase rather than possession.

The numbers of offenders with prior misdemeanour convictions are likely undercounted because we did not have status information about juveniles sentenced to probation nor did we have information about persons who were convicted but not sentenced to probation or incarceration (eg, those sentenced only to pay a fine). It is also possible (though unlikely) that some of the offenders with a prior felony had their gun rights reinstated. Finally, it is also important to remember that this is a prison population. As such, our findings may not generalise to offenders who avoid imprisonment.

However, our sample comes from a large national survey of state prison inmates and contains extensive information on their prior criminal history. In addition, we have focused on the population that is most likely to be affected by the policy changes we considered by including only offenders who used a firearm in their current offence. 


\section{What is already known on the subject}

- Guns in the hands of high-risk individuals present a serious threat to public safety.

- Among high-income countries, the USA is unique in its extraordinarily high rate of firearm homicides.

- US federal law establishes minimum criteria for who may legally purchase and possess firearms; state laws vary widely in this regard.

\section{What this study adds}

- This study is the first to use data on incarcerated gun offenders' age and criminal histories to examine the potential benefits from strengthening the criteria for legal firearm possession.

- Nearly three of every 10 gun offenders in the 13 US states with the least stringent criteria for legal gun ownership would have been prohibited from purchasing or possessing a firearm when they committed their most recent offence if their states had more restrictive laws in place.

- Offenders for whom access to firearms was legal under current standards were five times more likely to have obtained their gun from a gun store or pawnshop than were offenders who were prohibited under current state or federal law.

Our findings indicate that stricter gun ownership laws in states with the lowest standards would have made firearm possession illegal for many who used a gun to commit a crime. We are uncertain about the degree to which stricter legal standards for firearm possession might deter criminal gun possession and use. But, adding barriers for the acquisition of guns by high-risk persons is an underused potential intervention.

Funding This study was funded by a grant from The Joyce Foundation. Grant no: 07-30160.

\section{Competing interests None.}

Ethics approval Ethics approval was provided by the Johns Hopkins Bloomberg School of Public Health Institutional Review Board.

Provenance and peer review Not commissioned; externally peer reviewed.

Data sharing statement The study analyses data from a publically-available secondary database.

\section{REFERENCES}

1. Centers for Disease Control and Prevention. Web-based injury statistics Query and reporting System (WISOARS). National Center for Injury Prevention and Control,
Centers for Disease Control and Prevention (producer), 2007. http://www.cdc.gov/ ncipc/wisqars (accessed 10 Nov 2011).

2. Richardson EG, Hemenway D. Homicide, suicide, and unintentional firearm fatality: comparing the United States with other high-income countries, 2003. J Trauma 2011;70:238-43

3. 18 U.S.C. §922(g). 2011.

4. Vernick JS, Webster DW, Vittes KA. Law and policy approaches to keep guns away from high risk people. In: Culhane JG, ed. Social Issues, Welfare Consequences, and Public Health Law. New York: Cambridge University Press, 2010.

5. Berk R, Sherman L, Barnes G, et al. Forecasting murder within a population of probationers and parolees: a high stakes application of statistical learning. J Roy Stat Soc 2009:172:191-211.

6. Cook PJ, Ludwig J, Braga AA. Criminal records of homicide offenders. JAMA 2005:294:598-601.

7. Huebner B, Varano S, Barnes G, et al. Gangs, guns, and drugs: recidivism among serious young offenders. Criminol Publ Pol 2007;6:187-222.

8. Lucker GW, Holt VL, Kruzich DJ, et al. The prevalence of antisocial behavior among U.S. Army DWI offenders. J Stud Alc 1991;52:318-20.

9. Wintemute GJ, Drake CM, Beaumont JJ, et al. Prior misdemeanor convictions as a risk factor for later violent and firearm-related criminal activity among authorized purchasers of handguns. JAMA 1998;280:2083-7.

10. 18 U.S.C. $\S 922(s) .2011$.

11. Cook PJ, Ludwig J, Venkatesh S, et al. Underground gun markets. Econ J 2007:117:F588-618.

12. Wright JD, Rossi PH. Armed and Considered Dangerous. Armed and Considered Dangerous: A Survey of Felons and their Firearms. New York: Aldine de Gruyter, 1994.

13. Webster DW, Freed LH, Frattaroli S, et al. How delinquent youth acquire guns: initia versus most recent gun acquisitions. J Urban Health 2002;79:60-9.

14. U.S. Department of Justice. Bureau of Justice Statistics, Survey of Inmates in State and Federal Correctional Facilities, 2004. Ann Arbor, Ml: Inter-university Consortium for Political and Social Research [producer and distributor], 2007. doi:10.3886/ICPSR04572

15. U.S. Department of Justice. Bureau of Justice Statistics, Survey of Inmates in State and Federal Correctional Facilities, 2004. Codebook. Ann Arbor, MI: Interuniversity Consortium for Political and Social Research [producer and distributor]. http://dx.doi.org/10.3886/ICPSR04572.v1

16. Glaze LE, Maruschak LM. Parents in prison and their Minor Children. Washington, DC: U.S. Department of Justice, Bureau of Justice Statistics, 2008. Report No.: NCJ 222984.

17. Leigey ME, Reed KL. A woman's life before serving life: examining the negative preincarceration life events of female life-sentenced inmates. Women Crim Just 2010;20:302-22

18. Noonan ME, Mumola CJ. Veterans in State and Federal Prisons, 2004. Special Report. Washington, DC: U.S. Department of Justice, Bureau of Justice Statistics, 2007. Report No.: NCJ 217199.

19. Survey of State Procedures Related to Firearm Sales, Midyear 2004. Washington, DC National Institute of Justice, Bureau of Justice Statistics, 2005. Report No.: NC 209288.

20. 18 U.S.C. $\$ 922(d)(9) .2011$

21. 18 U.S.C. $\S 922(g)(9) .2011$

22. Vigdor ER, Mercy JA. Do laws restricting access to firearms by domestic violence offenders prevent intimate partner homicide? Eval Rev 2006;30:313-46

23. Webster DW, Vernick JS. Keeping firearms from drug and alcohol abusers. Inj Prev 2009:15:425-7.

24. N.M. Stat Ann. §30-7-2.2. 2004

25. Wis. Stat. \$941.29. 2004

26. Teret SP, Webster DW, Vernick JS, et al. Support for new policies to regulate firearms: results of two national surveys. N Engl J Med 1998;339:813-18.

27. Vernick JS, Rutkow L, Webster DW, et al. Changing the constitutional landscape for firearms: the Supreme Court's recent Second Amendment decisions. Am J Public Health 2011:101:2021-6.

28. Cook PJ, Molliconi S, Cole TB. Regulating gun markets. J Crim Law Criminol 1995;86:59-92.

29. Webster DW, Vernick JS, Bulzacchelli MT. Effects of state-level firearm seller accountability policies on firearm trafficking. J Urban Health 2009;86:525-37. 